\title{
A QUESTION MODULE FOR ASSESSING COMMUNITY STIGMA TOWARDS HIV IN RURAL INDIA
}

\author{
CAROL VLASSOFF*, MITCHELL G. WEISS $†$ AND SHOBHA RAO \\ *Department of Epidemiology and Community Medicine, University of Ottawa, Ontario, \\ Canada, $\dagger$ Department of Epidemiology and Public Health, Swiss Tropical and Public \\ Health Institute, University of Basel, Switzerland and $\ddagger$ Department of Biometry and \\ Nutrition, Agharkar Research Institute, Pune, India
}

\begin{abstract}
Summary. This paper describes a simple question module to assess community stigma in rural India. Fear of stigma is known to prevent people from seeking HIV testing and to contribute to further disease transmission, yet relatively little attention has been paid to community stigma and ways of measuring it. The module, based on a vignette of a fictional HIV-positive woman, was administered to 494 married women and 186 unmarried male and female adolescents in a village in rural Maharashtra, India. To consider the usefulness of the question module, a series of hypotheses were developed based on the correlations found in other studies between HIV-related stigma and sociodemographic characteristics (age, education, discussion of HIV with others, knowing someone living with HIV, knowledge about its transmission and whether respondents acknowledged stigmatizing attitudes as their own or attributed them to others). Many of the study's hypotheses were confirmed. Among married women, correlates of stigma included older age, lack of discussion of HIV and lack of knowledge about transmission; among adolescents, lower education and lack of discussion of HIV were the most significant correlates. The paper concludes that the question module is a useful tool for investigating the impact of interventions to reduce stigma and augment social support for people living with HIV in rural India.
\end{abstract}

\section{Introduction}

According to recent estimates, 2.4 million people are living with HIV in India (UNAIDS, 2010). Prevalence is higher in urban $(0.35 \%)$ than in rural areas $(0.25 \%)$ (IIPS \& Macro International, 2007), although prevalence in rural areas (constituting $72 \%$ of India's population) still represents a large rural population infected and affected by HIV. It is widely believed that many more people in India may be living with undiagnosed HIV infection due to high levels of stigma and discrimination (AVERT, 2010), which inhibit early diagnosis and treatment. Moreover, the widespread prevalence of sexually transmitted infections (STI) in India (Bhattacharya, 2004; Ankivar et al., 2009), key risk 
factors for HIV infection, indicates that a considerable amount of undiagnosed HIV may exist, especially in rural areas.

Indian women are especially vulnerable to HIV and its consequences, for several reasons. Firstly, the typical chain of transmission is heterosexual, from female sex workers to male clients, who then pass on the infection to their wives (Kumar et al., 2005; Jha, 2008). Despite a popular belief that married women cannot contract HIV (Santhya \& Jejeebhoy, 2007), marriage is the main risk factor for Indian women (Newmann et al., 2000; Santhya \& Jejeebhoy, 2007). Secondly, cultural taboos against the open discussion of sexual issues and against premarital friendships and relationships between young men and women (Bhattacharya, 2004) make it especially difficult for girls to receive accurate and complete information about sexual health, including STI/HIV prevention. Thirdly, social pressures for women to marry and bear children at an early age, and the discouragement of discussion and negotiation of safe sexual practices, even within marriage, compound the susceptibility of women (Bhattacharya, 2004; Solomon et al., 2004). For these reasons, Newmann et al. (2000) concluded that Indian prevention and intervention strategies should focus on married, monogamous women whose HIV risk is entirely dependent on their husbands' behaviour.

In India, as elsewhere, fear of stigma acts as a barrier to HIV testing and counselling, resulting in late diagnosis, treatment and access to care and support, and sometimes in onward disease transmission. India's National Family Health Survey-3 (NFHS3) 2005-2006 (IIPS \& Macro International, 2007) reported that only $17 \%$ of women and $33 \%$ of men had a comprehensive knowledge about HIV prevention and transmission. Nationally, to the four questions relating to HIV-related stigma, the results were as follows: $74.5 \%$ said they would care for an HIV-positive relative, $60.2 \%$, that they would buy vegetables from someone infected by HIV, 73.9\% would allow an HIVpositive female teacher who was not visibly ill to continue teaching, and $63.9 \%$ were in favour of keeping a family member's positive HIV status a secret. However, only $34 \%$ of females and $37 \%$ of males gave non-stigmatizing answers on all four questions (IIPS \& Macro International, 2007).

For people infected with HIV, stigma inhibits disclosure to others (Chandra et al., 2003; Steward et al., 2008, 2011) and results in considerable shame, suffering and denial of human rights, dignity and quality of life (Mawar et al., 2005; Mahendra et al., 2007; Hossain \& Kippax, 2010). Indian women living with HIV, including those infected by their husbands, are more often blamed for their illness, and more stigmatized because of it, than men (Pallikadavath et al., 2005; Vlassoff et al., in press).

In light of these challenges, India's National AIDS Control Organization (NACO) identified, as one of its eight guiding principles, the 'creation of an enabling environment wherein those infected and affected by HIV could lead a life of dignity free from stigma and discrimination,' (NACO, 2006). It has implemented comprehensive educational and awareness programmes, including targeted interventions for populations at higher risk (sex workers, men who have sex with men, injecting drug users). It has also provided information about HIV with the goal of building behavioural skills for preventive practices in the general population (NIHFW \& NACO, 2007). However, the evaluation of the impact of these programmes has been limited by the lack of appropriate tools to assess stigma within the community. This paper describes an 
instrument for assessing community stigma which was found to show considerable promise in the context of rural Maharashtra.

\section{Measuring community stigma}

Stigma has been defined as '... a negative response to human differences. These may be obvious, visible signs of human behaviour, or they may be more subtle. If these are related to a health condition, we call this response "health-related stigma",' (ILEP, 2011 , p. 6). Globally, there is a plethora of literature on stigma related to HIV (Aggleton \& Parker, 2002; Bond et al., 2002; van Brakel, 2006), but relatively few studies have focused on stigma within the general community and ways of measuring it (Campbell et al., 2005; Nyblade \& MacQuarrie, 2006; van Brakel, 2006). Community stigma refers to perceived community norms about, and behaviour toward, people with HIV (Sivaram et al., 2009) affecting different dimensions of life, such as personal contact, interactions with family and wider social relations with other community members (Vlassoff et al., in press). Methodologies to assess stigma have focused mainly on experiences of HIVpositive people (Berger et al., 2001; Mak et al., 2007; Simbayi et al., 2007; Sayles et al., 2008; Steward et al., 2008; Kalichman et al., 2009; Logie \& Gadalla, 2009; Steward et al., 2011) or on those closely affected, including families and health providers (Emlet, 2006; Mahendra et al., 2007; Stein \& Li, 2008; Nyblade et al., 2009). A review of tools to measure HIV-related stigma found that most studies among the uninfected concentrated on health workers, care-givers and students (Earnshaw \& Chaudoir, 2009), rather than on the broader population.

Studies in various countries have linked community stigma to a number of sociodemographic variables. More stigma has been documented among older respondents (Chen et al., 2005; Genberg et al., 2008, Vlassoff et al., in press), and among those with lower levels of education (Letamo, 2003; Chen et al., 2005; Lau \& Tsui, 2005; Sullivan et al., 2010; Unnikrishnan et al., 2010). Discussion with others (UNAIDS, 2001; Genberg et al., 2009), knowing someone living with HIV (Herek \& Capitanio, 1997; Chen et al., 2005; Genberg et al., 2008; Visser et al., 2008; Sullivan et al., 2010) and knowledge about HIV transmission have also been linked to lower stigma (Herek et al., 2002; Ogden \& Nyblade 2005; Visser et al., 2008), although the latter finding is not consistent across all studies (Simpson et al., 1998; Brown et al., 2001; Chen et al., 2005; Li et al., 2007). Also, several researchers have also noted that people are more likely to attribute stigma to others than to themselves (Alicke, 1985; Taylor \& Brown, 1988; Visser et al., 2008).

It should be noted that, while caste and religion are important social categories in India, there is no empirical evidence that they influence HIV-related stigma at the community level. There is limited evidence, in fact, that HIV stigma has created a kind of caste in itself: 'HIV makes one caste. Even in the highest family HIV means rejection,' (Petney, 2010). As this paper is based on relationships that have been found to be significant elsewhere, caste and religion are not included. However, statistical tests (Chi-squared) of these relationships for the study population found no statistically significant associations between caste or religion and stigma, probably because the predominant caste was Maratha (66.3\%) and the predominant religion Hindu (93.2\%). 
The need for measures to assess interventions aimed at stigma reduction in Indian society has been widely recognized (Mawar et al., 2005; Pallikadavath et al., 2005; Schneider et al., 2007; Genberg et al., 2008; Pai et al., 2009). Stigma is a culturally prescribed concept, expressed in ways specific to communities. Although there are common features of stigma, it can only be understood within the cultural context in which it is experienced. This paper describes an instrument for assessing stigma that can be useful for future research and interventions in rural India, with the ultimate goal of enhancing social support for people living with, and affected by, HIV.

\section{Hypotheses}

Based on correlations between stigma and the socio-demographic variables noted above, several hypotheses were developed regarding probable relationships in this study. Age was expected to be inversely correlated with stigma, i.e. that older respondents would express more stigma than younger ones. Increasing education was anticipated to be linked with more discussion of HIV with others and with having seen an HIV-positive person. Knowledge about HIV was expected to be negatively associated with stigma, and it was hypothesized that greater stigma would be attributed to others than to oneself. It was further anticipated that more stigma would be expressed with respect to interactions involving close personal contact with HIV-positive people than to less intimate social interactions.

\section{Methods}

\section{The study area}

This study was carried out in 2007-2008 in rural Satara District, Maharashtra, which has one of the highest HIV rates in India. A surveillance study of antenatal clients at the District Hospital in 2007 found that 2\% of them were HIV-positive (the same prevalence as reported by NACO, 2006). The present research focused on married women and adolescents, two demographic groups considered to be at high risk for HIV infection (Santhya \& Jejeebhoy, 2007), in a rural community, where the first author had conducted earlier studies on women's reproductive health. It was initiated at a time when HIV prevention was receiving considerable media attention, especially on television. HIV was generally acknowledged in the community as a problem, and several villagers had died of AIDS. Married women were selected for this research because of their increased vulnerability to HIV and its consequences, compared with men.

An externally funded high school project on HIV prevention had been ongoing in the community for more than a year. Given the exposure of students to this project, the inclusion of adolescents in the study was considered both possible (i.e. socially acceptable) and important (i.e. to compare younger respondents of both sexes with older, married women). The first author's familiarity with the community made it possible to explore the sensitive issue of HIV-related stigma among these groups.

\section{The study population}

A census of the village population was conducted, from which lists of all currently married women, aged 15-49, and all unmarried adolescents, aged 15-19, were prepared. All married women who were still menstruating were eligible for the study and 
$99 \%$ of them $(n=494)$ agreed to participate. Samples of 100 adolescent girls and boys were randomly selected from the total population of 159 females and 192 males, both in and out of school, of whom 86 girls and 98 boys were interviewed.

The study took place over 6 months, from October 2007 to March 2008. Three research assistants were recruited from outside the village: two females for the female interviews, and a male assistant for the male interviews.

\section{The stigma module}

A series of questions were selected, based on the Explanatory Model Interview Catalogue (EMIC), shown to be useful in detecting community stigma toward different diseases and conditions (Weiss, 1997). The EMIC's value lies in 'its simplicity and its utility, which has been demonstrated in different cultural settings and with very different health conditions...,' (van Brakel, 2006, p. 310). The questions focused on a vignette, or short story, about an HIV-positive woman (Appendix). The use of a vignette about a fictional person living with an illness has been found to be useful in eliciting responses reflective of what people will do in real-life situations (Peabody \& Li, 2004; Li et al., 2006). Vignettes are particularly appropriate for stigmatizing diseases because they contextualize those affected within the daily life of the community, rather than as abstract entities such as 'people with HIV' (Vlassoff et al., 2000; ILEP, 2011).

The vignette in this study deliberately focused on a married woman, Pushpa, who had been infected by her husband. This subject of the vignette was intended to portray a typical situation in which the woman was inadvertently 'innocently' infected. It was recognized that Pushpa's situation might elicit more stigma and less empathy if she had engaged in culturally unacceptable behaviour such as an extramarital affair or sex work. On the other hand, on the basis of the research cited above, it was also considered that Pushpa could be blamed or victimized because she was a woman.

Respondents were informed that a story about a fictional person would be read to them and that they would be asked several questions about her. The questions about the vignette concerned how people in the community were likely to respond to Pushpa in different dimensions of life, including close personal interactions (purchasing a home-made snack), family interactions (invitation to a wedding) and more distant social interactions (worshipping together). Those who answered 'yes' to the questions were considered to express less stigma than those answering 'no'. Another question focused on discriminatory behaviour, and whether people would do or say something to hurt Pushpa. Space was provided on the questionnaires for qualitative responses and the interviewers encouraged respondents to elaborate on their answers. The stigmarelated questions were framed by questions concerning knowledge about HIV, whether respondents had discussed it with anyone and whether they had seen someone living with it.

\section{Pre-testing}

The vignette and question module were pre-tested in October 2007 among women and adolescents in two rural communities located $50 \mathrm{~km}$ and $70 \mathrm{~km}$ from the study community. Local health workers introduced the study to the respondents, and two 
research assistants conducted the interviews. A total of 28 questionnaires were pre-tested among eighteen married women aged 15-49, and ten unmarried adolescents (seven girls and three boys) aged 15-19. The respondents had no difficulty understanding and answering the questions, and only minor modifications were required after the pre-test.

\section{Statistical methods}

Data were double-entered, cleaned and analysed with SPSS. Bivariate analysis was conducted to examine differences in stigma expressed by married women and adolescents, using normal test of proportions. Logistic regression was then used to identify the factors associated with stigma. For the multivariate analysis, married respondents were classified into two groups for each independent variable: age: 15-29 and 30+; education: $0-8$ and $9+$ years of completed schooling; and 'Yes/No' for the following three variables: having discussed HIV with someone, having seen someone HIVpositive, and knowing at least one way of preventing HIV. The dependent variables were also classified into two groups, 1 being the less stigmatizing response and 0 the more stigmatizing. A stigma index was also calculated from the seven stigma-related questions, and further classified into two groups ( $0-2$, 'low', coded as 1 ; and 3-6, 'high', coded as 0 ). This was because roughly half the respondents $(59.8 \%)$ fell into the $0-2$ category. The same classifications were used for adolescent respondents, with the exception of education, which was grouped into $0-10$ and $11+$ years. Age was omitted for the adolescent group because of its narrow range (15-19). Significance levels of $p<0.05$ and $p<0.10$ were used.

It should be emphasized that the purpose of this study was to validate the stigma module by determining whether interactions found by other researchers were also identified by our stigma measures, rather than to examine the interactions among the socio-demographic (independent) variables themselves. Nonetheless, the multiple logistic regression yields adjusted odds ratios for each of the independent variables in the presence of all the other independent variables, which indirectly deals with their interaction, if any.

Ethical clearance for the study was obtained from the Research Ethics Board, University of Ottawa.

\section{Results}

The vignette was found to be appropriate and useful for introducing the topic of HIV and for focusing the respondents on a common issue. Respondents empathized with Pushpa, the case presented, and many added their own embellishments to the information provided. For example, one woman remarked, 'Pushpa didn't know her husband was suffering from AIDS. Otherwise she would not have continued having sexual relations with him.'

The frequency distributions of the independent socio-demographic variables are presented in Table 1. Among married respondents, $41 \%$ were under 30 years of age, and over half had more than eight years of schooling. Only $28 \%$ said they had discussed HIV with others, $37 \%$ said they had seen someone with HIV and $88 \%$ could name at least one HIV prevention method. Most women cited television as their prin- 
Table 1. Selected characteristics of married women $(N=494)$ and adolescents $(N=186)$, percentage distributions

\begin{tabular}{lcc}
\hline Characteristic & $\begin{array}{l}\text { Married } \\
\text { women }\end{array}$ & $\begin{array}{c}\text { Unmarried } \\
\text { adolescents }\end{array}$ \\
\hline Age group: 15-29 years & 41 & 100 \\
Education: 9+ years (adults); 10+ years (adolescents) & 59 & 58 \\
Discussed HIV with someone: Yes & 28 & 54 \\
Seen HIV+ person: Yes & 37 & 26 \\
Knowledge about HIV: Yes & 88 & 67 \\
\hline
\end{tabular}

cipal source of HIV-related information. Only 6\% said they had been close to someone infected with HIV (not shown in table).

Male and female adolescents were grouped to provide a larger sample for analysis, and because their answers were not significantly different with respect to the majority of the stigma-related questions. Adolescents had higher educational levels than older women: 58\% had more than 10 years' schooling, and many were still studying. Over half $(54 \%)$ had discussed HIV with someone, $26 \%$ said they had seen someone with HIV and $67 \%$ could name at least one prevention method.

Many respondents, both married women and adolescents, gave examples of how people with HIV had been treated in the community. The case of one HIV-affected couple was cited repeatedly. Rejected by family and friends, the pair had moved to a hut in the fields to die. However, the case of a young village woman who had contracted HIV from her husband (who had died soon after their marriage) was also frequently mentioned. She was doing well on treatment and now had a successful teaching career in another community. When she visited the village she was treated with affection and respect.

A comparison of the responses of married women and adolescents to the stigmarelated questions is presented in Table 2. Married women perceived and expressed a considerable amount of stigma, significantly more than adolescents on most questions. For example, 64\% of women said people would not buy food from Pushpa, compared with $38 \%$ of adolescents. Forty-seven per cent scored high on the stigma index compared with $26 \%$ of adolescents. However, there was no significant difference in responses to the question of whether people would say or do something to hurt Pushpa, all perceiving that they would.

Overall, respondents gave less stigmatizing responses themselves than they attributed to others. For instance, $40 \%$ of married women said that others would not invite Pushpa to a wedding, whereas the majority felt that she should be invited. Similarly, $21 \%$ of adolescents felt that Chhaya would refuse to accompany Pushpa to the temple, whereas only $9 \%$ endorsed this behaviour. Interestingly, while both women and adolescents generally failed to endorse community stigma, and many, in their qualitative comments, lamented its existence, they appeared to accept this situation without expressing any feelings of obligation to act upon it. 
Table 2. Percentage of married women, aged 15-49 $(N=494)$, and of unmarried adolescents, aged 15-19 $(N=186)$, giving stigmatizing answers

\begin{tabular}{lcc}
\hline Question & $\begin{array}{c}\text { Married } \\
\text { women* }\end{array}$ & $\begin{array}{c}\text { Unmarried } \\
\text { adolescents* }\end{array}$ \\
\hline $\begin{array}{l}\text { Would people buy food from Pushpa? ('People buy') } \\
\text { No }\end{array}$ & $64^{\mathrm{a}}$ & $38^{\mathrm{b}}$ \\
$\begin{array}{l}\text { Would you buy food from Pushpa? ('You buy') } \\
\text { No }\end{array}$ & $41^{\mathrm{a}}$ & $16^{\mathrm{b}}$ \\
$\begin{array}{l}\text { Will Pushpa be invited to the wedding? ('Wedding-others') } \\
\text { No }\end{array}$ & $40^{\mathrm{a}}$ & $22^{\mathrm{b}}$ \\
$\begin{array}{l}\text { Should Pushpa be invited to the wedding? ('Wedding-endorse') } \\
\text { No }\end{array}$ & $21^{\mathrm{a}}$ & $5^{\mathrm{b}}$ \\
$\begin{array}{l}\text { Will Chhaya accompany Pushpa to the temple? ('Temple-others') } \\
\text { No }\end{array}$ & $41^{\mathrm{a}}$ & $21^{\mathrm{b}}$ \\
$\begin{array}{l}\text { Should Chhaya accompany Pushpa to the temple? ('Temple-endorse') } \\
\text { No }\end{array}$ & $21^{\mathrm{a}}$ & $9^{\mathrm{b}}$ \\
$\begin{array}{l}\text { Would people do or say anything to hurt Pushpa? ('Hurt Pushpa') } \\
\text { Yes }\end{array}$ & $74^{\mathrm{a}}$ & $72^{\mathrm{a}}$ \\
Stigma index \\
High (3-6)
\end{tabular}

*Percentages with different superscripts ( $\mathrm{a}$ and $\mathrm{b}$ ) across rows are significantly different $(p<0.01)$, using normal test for proportions.

The multivariate logistic results for married women are presented in Table 3. Referring first to the individual stigma-related questions, the odds of giving stigmatizing responses increased with age. Older women expressed more stigma than younger women, the odds ranging from 1.4 to 2.5, but was not significant for one variable, 'hurt Pushpa'. Lack of discussion of HIV was significantly related to more risk of stigma on all but two questions ('wedding-others' and 'hurt Pushpa'). Those who had not seen someone with HIV were significantly more likely to express stigma on three questions ('weddingothers', 'wedding-endorse' and 'temple-others'). Lack of knowledge about HIV was significantly related to greater stigma on two questions ('you buy', 'temple-others'). Education was not significantly associated with any of the stigma questions, although the odds ratios (ORs) were higher than one in most cases. The questions regarding the respondents' own potential behaviour ('you buy') and judgements ('wedding-endorse' and 'temple-endorse') showed the highest ORs. For example, women who had not discussed HIV were 4.2 times less likely to purchase Pushpa's food than those who had.

Relationships with the stigma index were significant for three independent variables: age, discussion and knowledge about HIV. For the other two variables - education and having seen someone with HIV - the ORs were not significant but were in the expected direction.

The multivariate logistic analysis results for adolescents are presented in Table 4. It can be seen that adolescents with lower education expressed significantly higher stigma on all but one question ('hurt Pushpa'). Those who had not discussed HIV with anyone 
Table 3. Adjusted odds ratios (OR) of factors associated with stigmatizing responses among married women, aged $15-49(N=494)$

\begin{tabular}{|c|c|c|c|c|c|c|c|c|}
\hline $\begin{array}{l}\text { Socio-demographic } \\
\text { variable }\end{array}$ & $\begin{array}{l}\text { People buy } \\
\text { OR (CI) }\end{array}$ & $\begin{array}{l}\text { You buy } \\
\text { OR (CI) }\end{array}$ & $\begin{array}{l}\text { Wedding-others } \\
\text { OR }(\mathrm{CI})\end{array}$ & $\begin{array}{c}\text { Wedding-endorse } \\
\text { OR }(\mathrm{CI})\end{array}$ & $\begin{array}{l}\text { Temple-others } \\
\text { OR }(\mathrm{CI})\end{array}$ & $\begin{array}{l}\text { Temple-endorse } \\
\text { OR (CI) }\end{array}$ & $\begin{array}{l}\text { Hurt Pushpa } \\
\text { OR (CI) }\end{array}$ & $\begin{array}{c}\text { Stigma index } \\
\text { OR (CI) }\end{array}$ \\
\hline \multicolumn{9}{|l|}{ Age group } \\
\hline $30+$ & $\begin{array}{c}1.62^{* *} \\
(1.096-2.404)\end{array}$ & $\begin{array}{c}2.17^{* *} \\
(1.436-3.275)\end{array}$ & $\begin{array}{c}1.43 * \\
(0.963-2.131)\end{array}$ & $\begin{array}{c}2.53 * * \\
(1.491-4.306)\end{array}$ & $\begin{array}{c}1.84^{* *} \\
(1.231-2.760)\end{array}$ & $\begin{array}{c}1.85^{* *} \\
(1.120-3.042)\end{array}$ & $\begin{array}{c}1.13 \\
(0.737-1.735)\end{array}$ & $\begin{array}{c}1.74 * * \\
(1.151-2.624)\end{array}$ \\
\hline \multicolumn{9}{|l|}{$\begin{array}{l}\text { Years of education } \\
9+\text { (Ref.) }\end{array}$} \\
\hline $0-8$ & $\begin{array}{c}1.16 \\
(0.787-1.71)\end{array}$ & $\begin{array}{c}1.35 \\
(0.908-2.000)\end{array}$ & $\begin{array}{c}0.860 \\
(0.585-1.264)\end{array}$ & $\begin{array}{c}1.32 \\
(0.829-2.098)\end{array}$ & $\begin{array}{c}1.18 \\
(0.797-1.735)\end{array}$ & $\begin{array}{c}1.09 \\
(0.690-1.719)\end{array}$ & $\begin{array}{c}1.35 \\
(0.880-2.084)\end{array}$ & $\begin{array}{c}1.14 \\
(0.753-1.718)\end{array}$ \\
\hline \multicolumn{9}{|l|}{$\begin{array}{l}\text { Discussed HIV } \\
\text { Yes (Ref.) }\end{array}$} \\
\hline No & $\begin{array}{c}1.57^{* *} \\
(1.018-2.441)\end{array}$ & $\begin{array}{c}4.20^{* *} \\
(2.465-7.154)\end{array}$ & $\begin{array}{c}1.45 \\
(0.910-2.308)\end{array}$ & $\begin{array}{c}2.37 * * \\
(1.205-4.673)\end{array}$ & $\begin{array}{c}1.51^{*} \\
(0.942-2.408)\end{array}$ & $\begin{array}{c}3.34 * * \\
(1.674-6.677)\end{array}$ & $\begin{array}{c}0.68 \\
(0.410-1.115)\end{array}$ & $\begin{array}{c}2.19 * * \\
(1.360-3.509)\end{array}$ \\
\hline \multicolumn{9}{|l|}{$\begin{array}{l}\text { Seen HIV+ person } \\
\quad \text { Yes (Ref.) }\end{array}$} \\
\hline No & $\begin{array}{c}1.40 \\
(0.932-2.101)\end{array}$ & $\begin{array}{c}1.09 \\
(0.706-1.662)\end{array}$ & $\begin{array}{c}1.47 * \\
(0.967-2.221)\end{array}$ & $\begin{array}{c}1.69 * * \\
(0.996-2.858)\end{array}$ & $\begin{array}{c}1.44 * \\
(0.947-2.180)\end{array}$ & $\begin{array}{c}1.13 \\
(0.688-1.863)\end{array}$ & $\begin{array}{c}1.36 \\
(0.877-2.110)\end{array}$ & $\begin{array}{c}1.20 \\
(0.784-1.845)\end{array}$ \\
\hline \multicolumn{9}{|l|}{$\begin{array}{l}\text { HIV knowledge } \\
\text { Yes (Ref.) }\end{array}$} \\
\hline No & $\begin{array}{c}1.70 \\
(0.851-3.379)\end{array}$ & $\begin{array}{c}2.26^{* *} \\
(1.207-4.244)\end{array}$ & $\begin{array}{c}1.36 \\
(0.749-2.479)\end{array}$ & $\begin{array}{c}1.39 \\
(0.726-2.667)\end{array}$ & $\begin{array}{c}2.07 * * \\
(1.105-3.872)\end{array}$ & $\begin{array}{c}1.12 \\
(0.580-2.171)\end{array}$ & $\begin{array}{c}1.11 \\
(0.550-2.246)\end{array}$ & $\begin{array}{c}1.97^{*} \\
(0.955-4.044)\end{array}$ \\
\hline
\end{tabular}

${ }^{* *} p<0.05 ; * p<0.1$. 
Table 4. Adjusted odds ratios (OR) of factors associated with stigmatizing responses among unmarried adolescents, aged $15-19(N=186)$

\begin{tabular}{|c|c|c|c|c|c|c|c|c|}
\hline $\begin{array}{l}\text { Socio-demographic } \\
\text { variable }\end{array}$ & $\begin{array}{l}\text { People buy } \\
\text { OR (CI) }\end{array}$ & $\begin{array}{l}\text { You buy } \\
\text { OR (CI) }\end{array}$ & $\begin{array}{l}\text { Wedding-others } \\
\text { OR (CI) }\end{array}$ & $\begin{array}{l}\text { Wedding-endorse } \\
\text { OR (CI) }\end{array}$ & $\begin{array}{l}\text { Temple-others } \\
\text { OR (CI) }\end{array}$ & $\begin{array}{l}\text { Temple-endorse } \\
\text { OR }(\mathrm{CI})\end{array}$ & $\begin{array}{l}\text { Hurt Pushpa } \\
\text { OR (CI) }\end{array}$ & $\begin{array}{l}\text { Stigma index } \\
\text { OR }(\mathrm{CI})\end{array}$ \\
\hline \multicolumn{9}{|l|}{$\begin{array}{l}\text { Years of education } \\
11+\text { (Ref.) }\end{array}$} \\
\hline $0-10$ & $\begin{array}{c}2.91 * * \\
(1.561-5.43)\end{array}$ & $\begin{array}{c}16.69^{* *} \\
(4.732-58.778)\end{array}$ & $\begin{array}{c}4.22 * * \\
(1.941-9.180)\end{array}$ & $\begin{array}{c}4.48^{*} \\
(0.864-23.259)\end{array}$ & $\begin{array}{c}2.87 * * \\
(1.342-6.152)\end{array}$ & $\begin{array}{c}3.79 * * \\
(1.140-12.633)\end{array}$ & $\begin{array}{c}1.34 \\
(0.667-2.699)\end{array}$ & $\begin{array}{c}5.05^{* *} \\
(2.396-10.649)\end{array}$ \\
\hline \multicolumn{9}{|l|}{ Discussed HIV } \\
\hline No & $\begin{array}{c}1.38 \\
(0.0727-6.277)\end{array}$ & $\begin{array}{c}2.38^{*} \\
(0.904-7.154)\end{array}$ & $\begin{array}{c}1.48 \\
(0.679-3.232)\end{array}$ & $\begin{array}{c}0.821 \\
(0.201-3.573)\end{array}$ & $\begin{array}{c}2.57 * * \\
(1.167-5.675)\end{array}$ & $\begin{array}{c}1.31 \\
(0.426-4.030)\end{array}$ & $\begin{array}{c}0.315^{* *} \\
(0.153-0.646)\end{array}$ & $\begin{array}{c}1.49 \\
(0.701-3.166)\end{array}$ \\
\hline \multicolumn{9}{|l|}{$\begin{array}{l}\text { Seen HIV+ person } \\
\text { Yes (Ref.) }\end{array}$} \\
\hline No & $\begin{array}{c}1.02 \\
(0.485-2.124)\end{array}$ & $\begin{array}{c}3.52 \\
(0.718-17.27)\end{array}$ & $\begin{array}{c}3.09^{* *} \\
(0.983-9.720)\end{array}$ & $\begin{array}{c}9.265 \times 10^{-7} \\
(000)\end{array}$ & $\begin{array}{c}1.42 \\
(0.523-3.876)\end{array}$ & $\begin{array}{c}4.18 \\
(0.507-34.421)\end{array}$ & $\begin{array}{c}2.22 * * \\
(1.011-4.867)\end{array}$ & $\begin{array}{c}2.46^{*} \\
(0.893-6.753)\end{array}$ \\
\hline \multicolumn{9}{|l|}{$\begin{array}{l}\text { HIV knowledge } \\
\text { Yes (Ref.) }\end{array}$} \\
\hline No & $\begin{array}{c}1.13 \\
(0.588-2.188)\end{array}$ & $\begin{array}{c}1.02 \\
(0.394-2.619)\end{array}$ & $\begin{array}{c}1.403 \\
(0.641-3.068)\end{array}$ & $\begin{array}{c}1.38 \\
(0.337-5.648)\end{array}$ & $\begin{array}{c}1.12 \\
(0.511-2.455)\end{array}$ & $\begin{array}{c}1.90 \\
(0.644-5.586)\end{array}$ & $\begin{array}{c}0.713 \\
(0.354-1.436)\end{array}$ & $\begin{array}{c}0.64 \\
(0.286-1.424)\end{array}$ \\
\hline
\end{tabular}

${ }^{* *} p<0.05 ;{ }^{*} p<0.1$. 
expressed significantly higher stigma on two of the questions ('you buy' and 'templeothers'). However, on the 'hurt Pushpa' question, discussion was significantly related to higher stigma. Those who had never seen an HIV-positive person expressed significantly more stigma on two questions ('wedding-others' and 'hurt Pushpa'). While no other relationships achieved statistical significance, most of the ORs were in the expected direction.

With regard to the stigma index, relationships were significant for both education and having seen someone with HIV, while the relationships with the other two variables (discussion of HIV and knowledge of HIV) were in the expected direction.

\section{Discussion}

The above results demonstrate that the goal of reducing stigma, already a national priority in India, is an urgent one, and that programmes aimed to reduce it need to be targeted at the general community as well as specific groups. Intervention programmes need to be accompanied by an understanding of the nature of stigma in the general population and the characteristics of community members who enact, endorse and accept stigma. This study has proposed a module with a few simple questions that can throw light upon and assess these dimensions of stigma.

The majority of this study's hypotheses, based on the findings of other studies, were confirmed. Age, discussion with others and knowledge about HIV were the most important predictors of stigma for married women, whereas education and discussion about HIV were the best predictors among adolescents. The lack of significant correlation between education and stigma among married women may be because information about HIV was not part of the traditional school curricula, whereas adolescents had benefited from the HIV prevention project. This difference is further indicated by the positive relationship between knowledge about HIV and lower stigma among married women, whereas for adolescents, education was a distinguishing variable. People were more likely to attribute stigma to others than to themselves, also in line with the findings of others (Alicke, 1985; Taylor \& Brown, 1988; Visser et al., 2008). Generally, respondents exhibited more sympathy than blame with respect to their own viewpoints, but affirmed emphatically the existence of community stigma. The endorsement of community stigma in some cases, and the general acceptance of its existence without exhibiting any need to confront the situation, indicated a general lack of ownership of the problem by community members.

As expected, more stigma was elicited from the questions regarding more intimate social relationships. For example, the questions about a marriage invitation and accompanying Pushpa to the temple educed less stigmatizing responses than the questions regarding buying food from an HIV-positive person. A greater number of significant relationships were found for married women than for adolescents, probably due to the larger sample size and their greater range of responses to the stigma-related questions.

It can be concluded that this module is a promising tool for future research on community stigma toward HIV in rural India, and for the assessment of HIV-related interventions, for several reasons. Firstly, the culturally appropriate vignette allowed respondents to imagine and relate to the subject as a familiar person, while being free 
to distance themselves sufficiently to answer sensitive questions. Secondly, the findings are consistent with those of other studies that have found variations in stigma by socio-demographic characteristics, demonstrating the module's strength as a stigmadiscriminating tool and its capacity for determining where interventions may be most useful. For example, discussion of HIV was found to be strongly associated with lower stigma, consistent with the observations of Genberg et al. (2009) and UNAIDS (2001). Hence, expanding opportunities for HIV discussion is a key recommendation. Thirdly, the combination of quantitative and qualitative, explanatory responses can help identify different degrees of stigma requiring different levels of intervention (Weiss, 2008). For example, the prevalence and acceptance of hurtful behaviour in the community indicates the need for changes at both legal and normative levels. Fourthly, the module was found to be applicable to different populations of diverse age and sex composition. Finally, it is short, easy to use and capable of yielding results quickly.

A problem shared by all stigma measures is the degree to which they reflect actual stigma. People may under-report their own stigmatizing feelings, perceiving themselves to be less negative than others. In this study, the fictional situation in the vignette may have created a 'comfortable' distance between the respondent and the case presented, resulting in answers less judgemental than might be true in real-life situations. Such answers, however, are likely to underestimate, rather than overestimate, stigma, indicating that when stigma is widely acknowledged, as in this study, it is a significant problem to be addressed.

It would be interesting to further test this instrument with a male vignette in the rural Indian setting, in order to compare sex differences in people's responses. While it might be expected that stigma against a male vignette would be less pronounced, variations in the expression of stigma would probably be seen with respect the different situations presented in the questions. It would also be interesting to adapt this module to other settings as well, using culturally specific examples, while retaining the same overall dimensions of stigma used in this study.

\section{Acknowledgments}

The authors wish to thank the Swiss Tropical and Public Health Institute, University of Basel, Switzerland, for its financial and technical support for this project, and the Agharkar Research Institute, India, for its institutional and logistical assistance. The help of Ms Sangita Mohite, Ms Chhaya Sawant and Mr Nitiraj Sable, research assistants, is greatly appreciated, as is the constant co-operation and participation of the village people in this study.

\section{References}

Aggleton, P. \& Parker, R. (2002) A Conceptual Framework and Basis for Action: HIV|AIDS Stigma and Discrimination. UNAIDS, Geneva.

Alicke, M. D. (1985) Global self-evaluation as determined by the desirability and controllability of trait adjectives. Journal of Personality and Social Psychology 49(6), 1621-1630.

Anvikar, A. R., Rao, V. G., Savargaonkar, D. D., Bhondeley, M. K., Tiwari, B., Karkare, A. et al. (2009) Seroprevalence of sexually transmitted viruses in the tribal population of Central India. International Journal of Infectious Diseases 13(1), 37-39. 
AVERT (AVERTing HIV and AIDS) (2010) India HIV \& AIDS Statistics. URL: http://www. avert.org/india-hiv-aids-statistics.htm.

Berger, B. E., Ferrans, C. E. \& Lashley, F. R. (2001) Measuring stigma in people with HIV: psychometric assessment of the HIV stigma scale. Research in Nursing and Health 24(6), 518-529.

Bhattacharya, G. (2004) Sociocultural and behavioral contexts of condom use in heterosexual married couples in India: challenges to the HIV prevention program. Health Education \& Behavior 31(1), 101-117.

Bond, V., Chase, E. \& Aggleton, P. (2002) Stigma, HIV/AIDS and prevention of mother-to-child transmission in Zambia. Evaluation and Program Planning 25(4), 347-356.

Bos, A. E. R., Schaalma, H. P. \& Pryor, J. B. (2008) Reducing AIDS-related stigma in developing countries: the importance of theory- and evidence-based interventions. Psychology, Health and Medicine 13(4), 450-460.

Brown , L., Macintyre, K. \& Trujillo, L. (2001) Interventions to reduce HIV/AIDS stigma: what have we learned? AIDS Education and Prevention 15(1), 49-69.

Campbell, C., Foulis, C., Maimane, S. \& Sibiya, Z. (2005) I have an evil child at my house: stigma and HIV/AIDS management in a South African community. American Journal of Public Health 95(5), 808-815.

Chandra, P. S., Deepthivarma, S. \& Manjula, V. (2003) Disclosure of HIV infection in South India: patterns, reasons and reactions. AIDS Care 15(2), 207-215.

Chen, J., Choe, M. K., Chen, S. \& Zhang, S. (2005) Community environment and HIV/AIDSrelated stigma in China. AIDS Education and Prevention 17(1), 1-11.

Earnshaw, V. \& Chaudoir, S. R. (2009) From conceptualizing to measuring HIV stigma: a review of HIV stigma mechanism measures. AIDS and Behavior 13, 1160-1177.

Emlet, C. A. (2006) A comparison of HIV stigma and disclosure patterns between older and younger adults living with HIV/AIDS. AIDS Patient Care and STDs 20(5), 350-358.

Genberg, B. L., Kawichai, S., Chingono, A., Sendah, M., Chariyalertsak, S., Konda et al. (2008) Assessing HIV/AIDS stigma and discrimination in developing countries. AIDS and Behavior 12, 772-780.

Government of India (2007) Census of India, 2001. Registrar General \& Census Commissioner India. URL: http://censusindia.gov.in/Census_Data_2001/India_at_glance/rural.aspx

Herek, G. M. \& Capianio, J. P. (1997) AIDS stigma and contact with persons with AIDS: effects of direct and vicarious contact. Journal of Applied Social Psychology 27(1), 1-36.

Herek, G. M., Capianio, J. P. \& Widaman, K. F. (2002) HIV-related stigma and knowledge in the United States: prevalence and trends, 1991-1999. American Journal of Public Health 92, 371-377.

Hossain, M. B. \& Kippax, S. (2010) HIV-related discriminatory attitudes of healthcare workers in Bangladesh. Journal of Health Population and Nutrition 28, 619-627.

ILEP (International Federation of Anti-Leprosy Associations) (2011) Guidelines to Reduce Stigma, Guide 1. ILEP and Netherlands Leprosy Relief (NLR), London/Amsterdam.

IIPS (Indian Institute for Population Sciences) \& Macro International (2007) National Family Health Survey (NFHS-3), 2005-2006, India: Key Findings. IIPS, Mumbai.

Jha, P. (2008) Sex, Money and Ideas: Twenty Years of Battling AIDS in India. Commonwealth Health Minister's Handbook, Commonwealth Secretariat.

Kalichman, S. C., Simbayi, L. C., Cloete, A., Mthembu, P. P., Mkhonta, R. N. \& Ginindza, T. (2009) Measuring AIDS stigma in people living with HIV/AIDS: the Internalized AIDSrelated Stigma Scale. AIDS Care 21, 87-93.

Lau, J. T. F. \& Tsui, H. Y. (2005) Discriminatory attitudes towards people living with HIV/ AIDS and associated factors: a population based study in the Chinese general population. Sexually Transmitted Infections 81, 113-119. 
Letamo, G. (2003) Prevalence of, and factors associated with, HIV/AIDS-related stigma and discriminatory attitudes in Botswana. Journal of Health, Population and Nutrition 21, 347357.

Li, L., Wu, Z., Zhao, Y., Lin, C., Detels, R. \& Wu, S. (2007) Using case vignettes to measure HIV-related stigma among health professionals in China. International Journal of Epidemiology 36, 178-184.

Logie, C. \& Gadalla, T. M. (2009) Meta-analysis of health and demographic correlates of stigma towards people living with HIV. AIDS Care 21, 742-753.

Mahendra, V. S., Gilborn, L., Bharat, S., Mudoi, R. J., Gupta, I., George, B. et al. (2007) Understanding and measuring AIDS-related stigma in health care settings: a developing country perspective. Journal of Social Aspects of HIV|AIDS 4(2), 616-625.

Mak, W. W. S., Cheung, R. Y. M., Law, R. W., Woo, J., Li, P. C. K. \& Chung, R. W. Y. (2007) Examining attribution model of self-stigma on social support and psychological well-being among people with HIV + /AIDS. Social Science \& Medicine 64, 1549-1559.

Mawar, N., Pandit, A., Sahay, A. \& Mahajan, U. (2005) The third phase of HIV pandemic: social consequences of HIV stigma and discrimination and future needs. Indian Journal of Medical Research 122(6), 471-484.

NACO (National AIDS Control Organization) (2006) National AIDS Control Program-Phase III (2006-11): Strategy and Implementation Plan. Ministry of Health \& Family Welfare, New Delhi. URL: http://siteresources.worldbank.org/INTHIVAIDS/Resources/3757981151090631807/2693180-1151090665111/2693181-1155742859198/India20V3.pdf

Newmann, S., Sarin, P., Kumaraswamy, N., Amalraj, E., Rogers, M., Madhivanan, P. et al. (2000) Marriage, monogamy and HIV: a profile of HIV-infected women in south India. International Journal of STD \& AIDS 11, 250-253.

NIHFW (National Institute of Health \& Family Welfare) \& NACO (National AIDS Control Organization) (2007) Annual HIV Sentinel Surveillance Country Report. New Delhi. URL: http://www.nacoonline.org/upload/NACO $\% 20$ PDF/HIV $\% 20$ Sentinel $\% 20$ Surveillance $\%$ 202006_India\%20Country\%20Report.pdf

Nyblade, L. \& MacQuarrie, K. (2006) Can we Measure HIV|AIDS-Related Stigma and Discrimination? Current Knowledge about Quantifying Stigma in Developing Countries. Policy Project, International Center for Research on Women (ICRW) and United States Agency for International Development (USAID), Washington, DC.

Nyblade, L., Stangl, A., Weiss, E. \& Ashburn, K. (2009) Combating HIV stigma in health care settings: what works? Journal of the International AIDS Society 12, 15. doi: 10.1186/17582652-12-15.

Ogden, J. \& Nyblade, L. (2005) Common at its Core: HIV-Related Stigma across Contexts. International Center for Research on Women (ICRW), Washington, DC.

Pai, N. P., Joshi, R., Moodie, E. E. M., Taksande, B., Kalantri, S. P., Pai, M., Tulsky, J. P. \& Reingold, A. (2009) Profile of adults seeking voluntary HIV testing and counseling in rural Central India: results from a hospital-based study. AIDS Care 21(3), 294-300.

Pallikadavath, S., Garda, L., Apte, H., Freedman, J. \& Stones, R. W. (2005) HIV/AIDS in rural India: context and health care needs. Journal of Biosocial Science 37, 641-655.

Peabody, J. W. \& Liu, A. (2004) A cross-national comparison of the quality of clinical care using vignettes. Health Policy and Planning 22(5), 294-302.

Petney, A. (2010) Experiences with HIVIAIDS and HIVIAIDS-Related Stigma among Infected and Affected Children in India. Health and Society in South Asia, Series No. 4, Heidelberg University, Germany.

Santhya, K. G. \& Jejeebhoy, S. J. (2007) Early marriage and HIV/AIDS: risk factors among young women in India. Economic \& Political Weekly 42(14), 1291-1297. 
Sayles, J. N., Hays, R. D., Sarkisian, C. A., Mahajan, A. P., Spritzer, K. L. \& Cunningham, W. E. (2008) Development and psychometric assessment of a multidimensional measure of internalized HIV stigma in a sample of HIV-positive adults. Aids and Behavior 12, 748-758.

Schneider, J. A., Saluja, G. S., Oruganti, G., Dass, S., Tolentino, J., Laumann, E. O. et al. (2007) HIV infection dynamics in rural Andhra Pradesh South India: a sexual-network analysis exploratory study. AIDS Care 19(9), 1171-1176.

Simbayi, L. C., Kalichman, S., Strebel, A., Cloetea, A., Hendaa, N. \& Mqeketoa, A. (2007) Internalized stigma, discrimination, and depression among men and women living with HIV/AIDS in Cape Town, South Africa. Social Science \& Medicine 64, 1823-1831.

Simpson, W. M., Johnstone, F. D., Boyd, F. M., Goldberg, D. J., Hart, G. J. \& Prescott, R. J. (1998) Uptake and acceptability of HIV testing: a randomized controlled trial of different methods of offering the test. British Medical Journal 316(7127), 262-267.

Sivaram, S., Zelaya, C., Shrikrishnan, A. K., Latkin, C., Go, V. F., Solomon, S. \& Celentano, D. (2009) Associations between social capital and HIV stigma in Chennai, India: considerations for prevention intervention design. AIDS Education and Prevention 21(3), 233-250.

Solomon, S., Chakraborty, A., D'Souza, Y. R. \& Detels R. (2004) A review of the HIV epidemic in India. AIDS Education and Prevention 16 (Supplement A), 155-169.

Stein, J. A. \& Li, L. (2008) Measuring HIV-related stigma among Chinese service providers: confirmatory factor analysis of a multidimensional scale. AIDS and Behavior 12, 789-795

Steward, W. T., Chandy, S., Singh, G., Panicker, S. T., Osmand, T. A., Heylen, E. \& Ekstrand, M. L. (2011) Depression is not an inevitable outcome of disclosure avoidance: HIV stigma and mental health in a cohort of HIV-infected individuals from Southern India. Psychology, Health and Medicine 16(1), 74-85.

Steward, W. T., Herek, G. M., Ramakrishna, J., Bharat, S., Chandy, S., Wrubel, J. \& Ekstrand, M. L. (2008) HIV-related stigma: adapting a theoretical framework for use in India. Social Science \& Medicine 67, 1225-1235.

Sullivan, S. G., Xu, J., Feng, Y., Su, S., Xu, C., Ding, X. et al. (2010) Stigmatizing attitudes and behaviors toward PLHA in rural China. AIDS Care 22(1), 104-111.

Taylor, S. E. \& Brown, J. D. (1988) Illusion and well-being: a social psychological perspective on mental health. Psychological Bulletin 103(2), 193-210.

UNAIDS (2001) Opening up the HIV|AIDS Epidemic. UNAIDS, Geneva.

UNAIDS (2010) Report on the Global AIDS Epidemic, 2010. UNAIDS, Geneva.

Unnikrishnan, B., Mithra, P. P., Rekha, T. \& Reshmi, B. (2010) Awareness and attitude of the general public toward HIV/AIDS in coastal Karnataka. Indian Journal of Community Medicine 35(1), 142-146.

Van Brakel, W. H. (2006) Measuring health-related stigma - a literature review. Psychology, Health and Medicine 11(3), 307-334.

Venkataramana, C. \& Sarada, P. V. (2001) Extent and speed of spread of HIV infection in India through the commercial sex networks: a perspective. Tropical Medicine \& International Health 6(12), 1040-1061.

Visser, M. J., Kershaw, T., Makin, J. D., Forsyth, B. W. C. (2008) Development of parallel scales to measure HIV-related stigma. AIDS and Behavior 12, 759-771.

Vlassoff, C., Weiss, M., Ovuga, E. B., Eneanya, C., Nwel, P. T., Babalola, S. S., Awedoba, A. K. et al. (2000) Gender and the stigma of onchocercal skin disease in Africa. Social Science \& Medicine 50, 1353-1368.

Vlassoff, C., Weiss, M., Rao, S., Ali, F. \& Prentice, T. (in press) HIV stigma in rural and tribal communities of Maharashtra, India. Journal of Health, Population and Nutrition.

Weiss, M. G. (1997) Explanatory Model Interview Catalogue: framework for comparative study of illness experience. Transcultural Psychiatry 34(2), 235-263.

Weiss, M. G. (2008) Stigma and the social burden of neglected tropical diseases. PLoS TWO E237. doi: 10.1371/journal.pntd.0000237. 


\section{Appendix}

Vignette and question module on HIV-related stigma

Pushpa is a 35-year-old Maratha woman from this village. She prepares and sells snacks at the market. You like her food and often buy one of her snacks. Her husband worked in Mumbai for eight years and recently returned to the village. He was sick with AIDS and Pushpa was also infected. She is not visibly ill.

1. Is there anything she could have done to prevent getting AIDS?

2. What is Pushpa's biggest problem?

3. If Pushpa asked you for advice about her problem, what would you suggest she do about it?

4. Would people buy food from her?

4.1. What about you? Would you buy food from her?

5. Pushpa has a friend, Manisha. Last year Manisha's daughter got married and Pushpa went to the wedding. Manisha's younger daughter is getting married this year. Will Pushpa be invited this time?

5.1. What is your own opinion? Do you think she should be invited?

6. Before her husband got sick, Pushpa always went to the temple on Thursdays with her friend, Chhaya. Will Chhaya still go with her?

6.1. What is your own opinion? Do you think Chhaya should still go with her?

7. Do you think people might say or do anything to hurt Pushpa because of her illness?

8. Now that you and others in the community know about AIDS, do you ever talk about it?

9. Have you ever seen someone with HIV/AIDS? We are not interested in knowing the person's name, just if you have seen someone with the illness.

9.1. Does anyone close to you have it? (PROBE ON CHARACTERISTICS: SEX, AGE)

9.2. Did they have any problems in the community because of their illness? What kinds?

IS THERE ANYTHING YOU WOULD LIKE TO ADD OR ASK? THANK YOU VERY MUCH FOR YOUR TIME AND CO-OPERATION. 